\title{
The Effect of Cooperative Learning Activities on Writing Skills of Iranian EFL Learners
}

\author{
Saeideh Ahangari", Zarrin Samadian \\ Department of English language, College of Persian Literature and Foreign Languages, Tabriz Branch, Islamic Azad University, \\ Tabriz, Iran \\ *Corresponding Author: s_ahangari@yahoo.com
}

Copyright (C) 2014 Horizon Research Publishing All rights reserved.

\begin{abstract}
Recent trends in second and foreign language pedagogy reflect a shift of focus from traditional teacher-dominated classes to more learner-centered contexts. Cooperative learning as opposed to individualistic and competitive learning, has been proclaimed as an effective and fruitful teaching method to improve the learner's linguistic, social and communicative competence. Cooperative learning requires learners to work together in groups to achieve a common goal and have the same measure of success. Maximizing the opportunities for student-student interaction with meaningful input and output in a supportive environment, cooperative learning has been confirmed as a desirable method for teaching all language elements. This study has investigated the impact of cooperative learning through Learning Together Model, proposed by Johnson and Johnson in 1987, on the writing skills of Iranian EFL learners. Thirty learners who were selected based on their English proficiency scores participated in this study. They were divided into two groups of experimental and control that took a pre-test and post-test in writing. The results of comparing their pre-test with their post-test scores indicated statistically significant differences between the control and experimental groups on the dependent variable and lent empirical support to the language teachers using cooperative learning as their teaching system. Some pedagogical implications can be offered as the results of the study. Language teachers by using cooperative learning techniques can create an enjoyable class of maximized participation and outcome. EFL learners in a cooperative learning environment, explore the language knowledge that they want to master.
\end{abstract}

Keywords Competitive Leaning, Cooperative Learning, Group Processing, Heterogeneous Grouping, Individual Accountability, Learning Together Model, Positive Interdependence

\section{Introduction}

Learning and teaching another language is a long and complex undertaking. In this process, we usually encounter a multitude of questions about the factors that affect our way of acting. These factors may be learners, teachers, and the way of teaching, the required time, the place and our purpose of learning another language. The world of teaching has changed drastically. The idea of using small groups in order to accomplish shared goals was nearly neglected in Grammar-Translation and Audio-Lingual Method[17]. Of course, there were some little attempts but they weren't systematic. Most fundamentally, schools are based on the relationship, and interactions are structured among everyone in the school environment determines how effective schools are. According to Brown[3], cooperation among students is part of the larger issue of the organizational structure of the school. In the last decade, one of the systematic attempts to activate the role of group working in order to reach shared goals has been cooperative learning.

According to Henley[7], Learning Together Model, introduced in 1987 by Johnson and Johnson, refers to having a team of four or five students working on a group project. He also states that this model provides group members with the opportunity for interaction, negotiation, discussion, consultation, and reflection on how team members contributed to the achievement of common goal. Obviously, these are among the significant properties of an ideal language class.

Cooperative Learning (CL) as opposed to individualistic and competitive learning has been proposed as an effective instructional approach which deals with the characteristics of learner-centered approaches[3]. Cooperative Learning requires learners to work together in groups to achieve a common goal and have the same measure of success[4]. This is in contrast with the traditional methods in which goals are individualistic rather than group -wide. Working together in groups promotes student's linguistic, cognitive, and social development[13].

According to Johnson and Holubec[11], cooperative learning refers to making small groups of students who work together to increase their own and their group mate's learning. In a cooperative learning group, students help each 
other to learn and understand the material, and encourage each other to do so. So Interaction, consultation, negotiation of meaning and explanation among students along with the feeling of responsibility toward self and peer learning are the main characteristics of Cooperative Learning groups.

\section{Cooperative Writing}

As Gabrielatos[5] stated in order to be able to select and use appropriate procedures and materials, as well as assess their learners needs and progress, teachers need to be clear regarding the desirable outcomes of a writing program and the processes involved in good writing. "First goal of writing like reading is to understand; only then one can make that understanding available to others in writing"[19]. Researchers report that cooperation typically leads to higher group and individual achievement, healthier relationships with peers, and greater psychological health and self-esteem[14].

In recent years there has been a renewed interest in the writing process, especially from a learning viewpoint. The poor, "ever declining" written production performance by writers of different age levels (from young children to college students) in a variety of text types (e.g., expository, argumentative, or narrative texts) was a strong motivating factor in the development of new models and hypotheses about the writing process (Zammuner, 1988, 1990, 1991.cited in [25]). Traditional theories about "composition" rules that were concerned with the written product only, were shown to be inadequate and were replaced by a new emphasis on the writing process and on the writer's (social) production context.

Zammuner[25], pointed that in the new approach, writing is conceptualized as the solution for an ill-structured problem; it is a recursive multiphase process, containing different levels, from low-order ones that generate lexical decisions and the like, to higher-order ones that are responsible for topic relevance and text structure. He also stated that this problem-solving process is guided by a writer's purpose and by his/her representation of his/her audience; the output of the process is constrained by the system's limited capacity e.g. the writer's linguistic and social skills, his/her attention resources, his/her knowledge of a specific topic.

However, as (Kroll and Well, 1983 cited in [5]) put it, there is a two-way traffic between theoretical research and educational classroom practice. Therefore, given that our main purpose is to influence the writing process in order to obtain higher quality products (texts), it would be unproductive to separate results about processes from those about products, or research on classroom practices from studies of cognitive processes.

According to Slavin[22] cooperative learning is very desirable because of its tendency to reduce peer competition and isolation, and to promote academic achievement and positive interrelationships. Therefore, cooperative learning helps students with learning disabilities, those who have social interaction difficulties. It is an instructional arrangement that fosters the practice and application collaborative skills within a natural setting (i.e., group activity). Thus, cooperative learning has been used extensively to promote writing achievement of students both with and without learning disabilities[22] Research (e.g. [10]) supports cooperative learning as an effective approach for including students with learning difficulties in classroom group work and promoting peer acceptance. However, some researchers (e.g.Andersen, Nelson, Fox, and Gruber, 1988; Rivera, Gillam, Goodwin, and Smith, 1996; Slavin, Madden, and Leavey, 1984 cited in[1]) caution teachers to integrate direct instruction and cooperative learning. Thus, in cooperative learning groups with proper instruction and preparation (i.e., previous direct instruction on skills), students with writing disabilities can benefit from peer interactions to learn writing skills and concepts.

Just as a teacher needs to teach academic skills, social skills also need to be directly addressed. Students who work in teams need

(a) an opportunity to work together cooperatively (where teamwork skills need to be manifested), (b) a motivation to engage in the teamwork skills (a reason to believe that such actions will be beneficial to them), and (c) some proficiency in using teamwork skills[15].

Rivers[21] states that, in order to give students opportunities to relate their own lives, activities and concerns to second language writing, teachers should stimulate work in groups, where students work together and learn from each other. Small-group writing tasks increase active student participation in which working with others in a harmonious way and open-mindedness about others' feelings and idea is emphasized. Students learn from their peers how to conceptualize ideas and interpret content. They constantly discuss their findings and refine them by peer's reflection, "through the checks and contributions of others, they learn to relate bodies of knowledge meaningfully, to make cultural observation refined by discussion and to evolve new and richer interpretations of material" [21].

Traditionally over the past century, schools have been developed as "mass-production" organizations that divided work into small component parts performed by individuals who worked separately from and, in many cases in completion with peers. Teachers worked alone, in their own set of curriculum materials. Students were assigned to one teacher for short segments of time such as one class period each day and/or one school year. Teachers and students alike were considered to be interchangeable parts in the organizational machine[12].

In order to solve the above mentioned problems, new and useful ways of teaching should be used in the process of learning and teaching languages. To do this, we should change our competitive and individualistic conditions in our classes to cooperative ones.

Some researchers have investigated the impact of cooperative activities on learners' skill improvement. For example Proto (2001) presented a study on cooperative 
writing response and self evaluation. He stated that giving working environment which offered the flexibility to shift focus to cooperative writing helped learners to synthetize product and process and capture the complexity of writing. In another study conducted by Burley (1998), he found that word processing alone has little effect on writing behavior; however, conferencing software (based on cooperative learning) seems to help create more authentic writing environment. It helps students identify and use varying learning styles of cooperative groups to successfully reach writing goals. Zammuner[25] proposed a study on individual and cooperative computer-writing and revision. The results of that study showed that children, especially when they revise their text with a peer, are able to carry out both local and more global revisions.

As English language teachers, the researchers have noticed some of the problems of students that can best be solved through group working and cooperation. Students can learn from each other at the same time that they learn from their teacher. So inspired by those ideas about the benefits of cooperative learning, the researchers intended to investigate the effect of using cooperative-learning activities on improving writing skill of university students in Maragheh Azad University, Iran.

\section{Research Questions}

As mentioned previously, Cooperative Learning is one of the techniques of language instruction, which results in mastering the content to be learned. As such, this research seeks to answer the following questions:

Q1: Do cooperative writing activities improve Iranian EFL Learners' writing performance?

Q2: Which components of Iranian EFL learners' writing product (content, organization, vocabulary, language use, mechanics) are mainly affected through the cooperative learning activities?

\section{Method}

\subsection{Participants}

To conduct this research study, the researcher selected 50 students of Islamic Azad University Maragheh Branch and examined their proficiency levels by giving a preliminary English Test (PET). Those whose scores ranged from 40 to 55 out of 60 were selected to participate in the study. Ninety percents of the participants were female and 10 percent were male, and their majors were teaching English. The participants in this study with an age range of 20 to 28 were in the intermediate level, based on their proficiency (PET) test. All participants came from a bilingual background i.e. Turkish and Persian. The participants were randomly assigned to two groups: a control group that received no cooperative learning activities and an experimental group that received cooperative learning activities.

\subsection{Instrumentation}

The text book used for both experimental and control groups was "The Practical Writing through Reading, intermediate level, by Bailey \& Powell[2]. The book was selected by the university administration for writing 1 course of the given students. The units of the mentioned book were taught for both experimental and control groups. Each unit started with a topic page including the topic of the unit, related exercises, and chapter focuses.

\subsection{The pre-test and post-test}

The writing test was selected from the participants' writing book which was used both as the pretest at the onset of the study and posttest at the end. The topic of the pre-test was (Describe the Reasons of coming to University and Your Plans for the Future). In this test, the participants were asked to write about 250 words. The scoring procedure was Analytic Scoring Method according to Jacobson writing checklist cited in Weigle[24]. Furthermore, according to Multiple Trait Method, in order to make sure of the reliability of the test, two different raters scored each paper. At the end of the study the participants were also asked to write on another topic from the same book (Describe Iranian Marriage Costumes). In this test, which was considered as the post-test the participants were asked to write about 250 words. The scoring procedure was the same as the pre-test.

\subsection{Procedure}

This part consisted of seven phases. First, a population of 50 Iranian university students participated in this study. In order to check their level of proficiency, the researcher gave the participants a preliminary English test (PET) that included 35 multiple choice reading questions and seven writing questions. According to their English language proficiency scores, 30 participants were chosen (those whose scores ranged from 40 to 55 out of 60 ), as the participants of the study. Afterwards these participants were divided into two groups of experimental and control and their homogeneity was checked by running an independent t-test for their proficiency scores. In the second phase, both groups were given a pre-test including writing about 250 words on the topic.

The third phase dealt with creating small teams among the experimental group according to the principles of cooperative learning. Regarding the students' pre-test scores, gender, and field of study, the researcher tried to make three equal teams out of 15 participants. That is, each small group included one weak student, who received below 50, three average students who received between 50 to 70 , and one high performance student who had got 70 to 100 in the pre-test. All teams included both male and female students. Consequently, the experimental group was divided into three 
teams, each with five members to work together for the purpose of the research.

The fourth phase concerned with familiarizing the teams with the principles of cooperative learning, particularly the Learning Together Model, proposed by Johnson and Johnson in 1987 and has been confirmed to be the most effective model of cooperative learning[16]. The five essential elements of cooperation and the benefits of cooperation over the competitive and individualistic learning were explained to them. This phase lasted for one 90 minutes session and most students promised to follow the principles since the method seemed a new and interesting one to them.

The fifth phase dealt with familiarizing students with their roles in the team along with the teacher's roles and expectations. Each member in a group was assigned to a role and each session the roles changed so that each member played all the roles during the treatment. The responsibility in each role was clearly discussed. It was hoped that giving the team members these roles and responsibilities would result in high quality learning and promoted positive interdependence among the learners[12].

During the sixth phase which lasted for 5 sessions, the learners were involved in real group activities. In each session they wrote about one topic. The classes were conducted according to the lesson plan for the experimental group. The plans included instructional objectives, a list of materials needed as well as specification of time required, group size, assignment to roles, and arrangement of the room. The lesson plan also included an explanation of tasks, procedures to structure positive interdependence and individual accountability, criteria for success, the social skills, expected behaviors as well as procedures for group monitoring and processing how well the group functioned.

Meanwhile the control group received the whole class instruction. That is, it was taught in a teacher-centered context according to their lesson plans. The lesson plans for the control group focused on writing the same material with the same instructional objectives. The plans also included opening, instruction, and closer.

Both the experimental and control groups' lesson plans addressed the same instructional objectives and were based on the same writing activities and exercises. However, the experimental plans provided opportunities for small group instruction and for sharing resources among team members. Conversely, students in control group worked individually and shared their answers with the class.

Finally, the seventh phase of the study was conducted after the treatment. Students in both control and experimental groups were administrated the same post-test; i.e. "Describe Iranian Marriage Customs".

\subsection{Design}

The research questions proposed in the present study requires a quasi experimental method of research. Accordingly, the study employed a pre-test and post-test, control group, and experimental group design while focusing on the variables of cooperative learning, with the specific emphasis on Learning Together Model as an independent variable and the participants' writing performance as a dependent variable which was hypothesized to be influenced by the independent variable.

\subsection{Data Analysis}

Having collected the data from the pre-test, and post-test, the researcher employed SPSS (version 15-evaluation) to analyze data. First descriptive statistics of each individual test was calculated. Then, it was compared with their pre-test performance to check whether learning had happened and how well each group had done. At the other stage, it was compared with different aspects of writing (content, organization, vocabulary, language use, and mechanics), to find which aspects of the writing skills have been strongly affected by cooperative activities.

The first data considered were the two groups of participants' proficiency scores which were compared through an independent t-test, the results of which are given in Table 1 below.

According to descriptive data in table 1, the mean score of the groups are approximately at the same level, and the results of the $\mathrm{t}$-test in Table $1(\mathrm{t}(28)=.729, \mathrm{P}=.472)$ show that the $\mathrm{P}$ value of (.472) is more than .05 , therefore it demonstrates that there is not a significant difference among two groups regarding their proficiency scores.

Table 1. T-test between Groups for Proficiency Scores

\begin{tabular}{|cc|c|c|c|c|c|c|}
\hline \multicolumn{2}{|c|}{ Group } & $\mathrm{N}$ & Mean & Std. Deviation & T & df & Sig. (2-tailed \\
\hline Proficiency & 1 & 15 & 46.13 & 4.96 & .729 & & 28 \\
Scores & 2 & 15 & 44.93 & 3.99 & & & .472 \\
\hline
\end{tabular}


Then the participants of both groups were asked to write a composition as a pre-test. After the treatment they were asked to write another composition as a post-test. The scoring procedure of both compositions was Analytic Scoring Method. Furthermore, according to Multiple Trait Method, in order to make sure of the reliability of the test, two different raters scored each paper. In order to check the reliability of the scores between two raters, reliability estimates for both pre-test and post-test between raters were calculated, which showed a high index of (.94) for the pre-test scores and (.98) for the post-test scores.

The first research question in this study addressed the effect of cooperative learning on writing skill of Iranian EFL learners.

For answering the first question, the researcher conducted an ANCOVA analysis between the post-test of both experimental and control groups. As the descriptive data in Table 2 shows, during the post-test the mean score of this experimental group was 88.80 , but the mean score of control group was 73.10. In order to see whether this difference was statistically significant, the researcher conducted an ANCOVA analysis, the results of which are presented in table 3 .

As it is clear in Table 3, the results of the ANCOVA implicates that there is a statistically significant difference among the performance of experimental group on the post test $\mathrm{F}(1,27)=59.66, \mathrm{P}=.000$, since $\mathrm{P}$ value is lower than .05. Therefore, the results confirmed that the cooperative learning activities in writing classes improve Iranian EFL learners' writing performance.

Table 2. Descriptive Statistics for the Post-test.

Writing Total Score ANCOVA.

Dependent Variable: post-total

\begin{tabular}{|c|c|c|c|}
\hline Group & Mean & Std. Deviation & $\mathrm{N}$ \\
\hline 1.00 & 73.1000 & 12.48885 & 15 \\
2.00 & 88.8000 & 8.87975 & 15 \\
Total & 80.9500 & 13.30825 & 30 \\
\hline
\end{tabular}

Table 3. ANCOVA Analysis for the Post-test Writing Total Score

Dependent Variable: post-total

\begin{tabular}{|c|c|c|c|c|c|}
\hline Source & $\begin{array}{c}\text { Type III Sum of } \\
\text { Squares }\end{array}$ & Df & Mean Square & F & Sig. \\
\hline Corrected Model & $3993.597^{\mathrm{a}}$ & 2 & 1996.798 & 47.186 & .000 \\
Intercept & 996.762 & 1 & 996.762 & 23.554 & .000 \\
Pre.total & 2144.922 & 1 & 2144.922 & 50.686 & .000 \\
Group & 2524.667 & 1 & 2524.667 & 59.660 & .000 \\
Error & 1142.578 & 27 & 42.318 & & \\
Total & 201723.250 & 30 & & & \\
Corrected Total & 5136.175 & 29 & & & \\
\hline
\end{tabular}

a. R Squared $=.778($ Adjusted R Squared $=.761)$

The second research question in this study aimed to examine the effect of cooperative learning activities on the components of EFL learners' writing performance. So this question is later on divided into five sub-questions each one dealing with one of the subcomponents of the scale. Question 2.1. was related to the content component of the writing as following:

Q2.1: Do cooperative writing activities have any effect on the content aspect of writing skill?

Table 4. Descriptive Statistics for the Content Component Dependent Variable: content-post

\begin{tabular}{|c|c|c|c|}
\hline Group & Mean & Std. Deviation & $\mathrm{N}$ \\
1.00 & 23.4000 & 4.40454 & 15 \\
2.00 & 26.7333 & 3.43234 & 15 \\
Total & 25.0667 & 4.23396 & 30 \\
\hline
\end{tabular}

By looking at the mean scores of the content component of learner's post-test in both experimental and control groups, it 
can be noticed that there has been considerable increase in the mean score of experimental group. As the descriptive data in Table 4 shows, during the post-test the mean score of the experimental group was 26.73 , but the mean score of control group was 23.40 out of 30 . In order to see whether this difference was statistically significant, the researcher conducted an ANCOVA analysis, the results of which are presented in table 5.

Table 5. ANCOVA Analysis for the Content Component

\begin{tabular}{|c|c|c|c|c|c|}
\hline Source & $\begin{array}{c}\text { Type III Sum of } \\
\text { Squares }\end{array}$ & Df & Mean Square & F & Sig. \\
\hline Corrected Model & $269.052^{\mathrm{a}}$ & 2 & 134.526 & 14.482 & .000 \\
Intercept & 214.139 & 1 & 214.139 & 23.052 & .000 \\
Content.pre & 185.719 & 1 & 185.719 & 19.993 & .000 \\
Group & 114.695 & 1 & 114.695 & 12.347 & .002 \\
Error & 250.814 & 27 & 9.289 & & \\
Total & 19370.000 & 30 & & & \\
Corrected Total & 519.867 & 29 & & & \\
\hline
\end{tabular}

a. $\mathrm{R}$ Squared $=.518($ Adjusted R Squared $=.482)$

As shown in Table 5, the difference was statistically significant. Therefore, the results reveal that Cooperative Learning activities had a significant effect on improving content component of writing skill. $\mathrm{F}(1,27)=12.347, \mathrm{P}=.002$

The third research question in this study investigated the effect of cooperative learning activities on the organization aspect of writing skill.

Q2.2: Do cooperative writing activities have any effect on the organization aspect of writing skill?

Table 6. Descriptive Statistics for the organization

\begin{tabular}{|c|c|c|c|}
\hline Group & Mean & Std. Deviation & $\mathrm{N}$ \\
\hline 1.00 & 16.0667 & 2.28244 & 15 \\
2.00 & 18.0000 & 2.07020 & 15 \\
Total & 17.0333 & 2.35597 & 30 \\
\hline
\end{tabular}

Regarding the differences among the mean score of organization component of learner's post-test in both experimental and control group in Table 6, during the post-test the mean score of this experimental group was 18.00, but the mean score of control group was 16.06 out of 20. In order to analyze the results an ANCOVA was conducted to compare total means of two groups in the post-test. Table 7 illustrates the results clearly.

Table 7. ANCOVA Analysis for the Organization Component

Dependent Variable: organ.post

\begin{tabular}{|c|c|c|c|c|c|}
\hline Source & $\begin{array}{c}\text { Type III Sum of } \\
\text { Squares }\end{array}$ & Df & Mean Square & F & Sig. \\
\hline Corrected Model & $118.594^{\mathrm{a}}$ & 2 & 59.297 & 37.784 & .000 \\
Intercept & 51.139 & 1 & 51.139 & 32.585 & .000 \\
Organ.pre & 90.560 & 1 & 90.560 & 57.705 & .000 \\
Group & 50.576 & 1 & 50.576 & 32.227 & .000 \\
Error & 42.373 & 27 & 1.569 & & \\
Total & 8865.000 & 30 & & & \\
Corrected Total & 160.967 & 29 & & & \\
\hline
\end{tabular}

a. $\quad$ R Squared $=.737$ (Adjusted R Squared $=.717$ )

The results of ANCOVA test displayed in Table 7, indicates that there is a significant difference among the organization mean scores of the two experimental and control group.

Therefore, the results reveal that Cooperative Learning activities had a significant effect on improving organization 
component of writing skill. $\mathrm{F}(1,27)=32.227, \mathrm{P}=.000$

The fourth research question in this study examined the effect of cooperative learning activities on the vocabulary aspect of writing skill.

Q2.3: Do cooperative writing activities have any effect on the vocabulary aspect of writing skill?

Table 8. Descriptive Statistics for the Vocabulary of Writing

\begin{tabular}{|c|c|c|c|}
\hline Group & Mean & Std. Deviation & $\mathrm{N}$ \\
\hline 1.00 & 13.8667 & 3.11372 & 15 \\
2.00 & 18.0000 & 2.23607 & 15 \\
Total & 15.9333 & 3.39303 & 30 \\
\hline
\end{tabular}

The obtained data of the post-tests of groups' vocabulary component in both experimental and control groups were analyzed through utilizing ANCOVA. Table 8 demonstrates the descriptive data for the performance of the groups on the post-test. During the post-test the mean score of this experimental group was 18.00, but the mean score of control group was 13.86 out of 20 . In order to see whether this difference was statistically significant, the researcher conducted an ANCOVA analysis, the results of which are presented in table 9.

Table 9. ANCOVA Analysis for the Vocabulary Component

Dependent Variable: vocab.post

\begin{tabular}{|c|c|c|c|c|c|}
\hline Source & $\begin{array}{c}\text { Type III Sum of } \\
\text { Squares }\end{array}$ & Df & Mean Square & F & Sig. \\
\hline Corrected Model & $157.926^{\mathrm{a}}$ & 2 & 78.963 & 12.118 & .000 \\
Intercept & 195.283 & 1 & 195.283 & 29.968 & .000 \\
Vocab.pre & 29.793 & 1 & 29.793 & 4.572 & .042 \\
Group & 155.085 & 1 & 155.085 & 23.799 & .000 \\
Error & 175.941 & 27 & 6.516 & & \\
Total & 7950.000 & 30 & & & \\
Corrected Total & 333.867 & 29 & & & \\
\hline
\end{tabular}

a. $\mathrm{R}$ Squared $=.473$ (Adjusted R Squared $=.434$ )

With regard to the findings obtained from conducted ANCOVA in Table 9, it becomes clear that Cooperative Learning activities had a significant effect on improving vocabulary component of writing skill. $F(1,27)=23.79, P=.000$

The fifth research question in this study investigated the effect of cooperative learning activities on the language use aspect of writing skill.

Q2.4: Do cooperative writing activities have any effect the language use aspect of writing skill?

Table 10. Descriptive Statistics for the Language Use Dependent Variable: use-post

\begin{tabular}{|c|c|c|c|}
\hline Group & Mean & Std. Deviation & $\mathrm{N}$ \\
\hline 1.00 & 15.9333 & 4.11386 & 15 \\
\hline 2.00 & 21.6000 & 3.11219 & 15 \\
\hline Total & 18.7667 & 4.59898 & 30 \\
\hline
\end{tabular}

To answer this question the researcher conducted an ANCOVA analysis between the Language use component of learner's post-test of both experimental and control groups. As the descriptive data in Table 10 shows, during the post-test the mean score of the experimental group was 21.60, but the mean score of control group was 15.93 out of 25 . In order to see whether this difference was statistically significant, the researcher conducted an ANCOVA analysis, the results of which are presented in table 11 . 
Table 11. ANCOVA Analysis for the Language Use Component

Dependent Variable: use.post

\begin{tabular}{|c|c|c|c|c|c|}
\hline Source & $\begin{array}{c}\text { Type III Sum of } \\
\text { Squares }\end{array}$ & Df & Mean Square & F & Sig. \\
\hline Corrected Model & $418.752^{\mathrm{a}}$ & 2 & 209.376 & 29.048 & .000 \\
Intercept & 293.375 & 1 & 293.375 & 40.702 & .000 \\
Use.pre & 177.919 & 1 & 177.919 & 24.684 & .000 \\
Group & 320.964 & 1 & 320.964 & 44.529 & .000 \\
Error & 194.614 & 27 & 7.208 & & \\
Total & 11179.000 & 30 & & & \\
Corrected Total & 613.367 & 29 & & \\
\hline
\end{tabular}

a. R Squared $=.683$ (Adjusted R Squared $=.659$ )

Based on the results obtained from the conducted ANCOVA in Table 11, we can conclude that the answer to the fifth research question in this study is positive, and the cooperative activities produced by participants enhanced the scores of their Language use. So Cooperative Learning activities had a significant effect on improving language use component of writing skill. $\mathrm{F}(1,27)=44.529, \mathrm{P}=.00$

The sixth research question in this study investigated the effect of cooperative learning activities on the mechanics aspect of writing skill.

Q2.5: Do cooperative writing activities have any effect the mechanics aspect of writing skill?

Table 12. Descriptive Statistics for the Mechanics of Writing

Dependent Variable: mech.post

\begin{tabular}{|c|c|c|c|}
\hline Group & Mean & Std. Deviation & $\mathrm{N}$ \\
\hline 1.00 & 3.2000 & 1.01419 & 15 \\
2.00 & 4.5333 & .63994 & 15 \\
Total & 3.8667 & 1.07425 & 30 \\
\hline
\end{tabular}

The mean score of mechanics component of learner's post-test in both experimental and control groups in Table 12 were 4.53 , and 3.20 out of 5 respectively. That is, the mean score of mechanics component in experimental group was more than that of control group.

Table 13. ANCOVA Analysis for the Mechanics Component

Dependent Variable: mech.post

\begin{tabular}{|c|c|c|c|c|c|}
\hline Source & $\begin{array}{c}\text { Type III Sum of } \\
\text { Squares }\end{array}$ & Df & Mean Square & F & Sig. \\
\hline Corrected Model & $22.038^{\mathrm{a}}$ & 2 & 11.019 & 26.033 & .000 \\
Intercept & 10.697 & 1 & 10.697 & 25.272 & .000 \\
Mech.pre & 8.705 & 1 & 8.705 & 20.565 & .000 \\
Group & 15.322 & 1 & 15.322 & 36.198 & .000 \\
Error & 11.429 & 27 & .423 & & \\
Total & 482.000 & 30 & & & \\
Corrected Total & 33.467 & 29 & & & \\
\hline
\end{tabular}

a. R Squared $=.659($ Adjusted R Squared $=.633)$

Finally, for mechanics measure, the results of the ANCOVA analysis in Table 13 above revealed the positive effect of Cooperative Learning activities on improving mechanics component of writing skill. $\mathrm{F}(1,27)=36.19, \mathrm{P}=.00$ 


\section{Discussion}

To answer the proposed research questions two homogeneous groups were chosen and one of them received the treatment, working together in small groups. The results of the given measurements after the treatment indicated a difference between the mean scores of the two groups. However, to be statistically confidant about the significance of the differences, the results were compared using the ANCOVA analysis. The value of observed $F$ was calculated using the means and standard deviations obtained from the post-test. The observed $\mathrm{F}$ was compared with the critical $\mathrm{P}$ in .05 level of significance with the $\mathrm{df}$ of $(1,27)$. Since the observed $\mathrm{F}$ was lower than .05 critical $\mathrm{P}$, the first research question was answered positively. Therefore, we could be statistically sure about the existence of a significant difference between the two group's performances after the treatment. Accordingly the outcomes of this study confirm the effect of cooperative learning activities on improving the components of writing skills i.e., (content, organization, vocabulary, language use, and mechanics). All of these five components were improved by using cooperative learning activities in the experimental group.

We can suggest that writing performance can be improved through small-group cooperative interaction among peers in a supportive and stress-reduced environment; working with small groups provides various quality and quantity of input, output, and correction along with the increase of face-to-face interaction. There is almost missing in traditional teacher-centered classes. Working in small group develops the learner's interaction and communicative skills such as active listening, speaking, and turn taking. Cooperative group work can also foster cognitive skills such as problem solving, discovery learning, and creativity. Working together provides a context for students to learn and practice social skills. Learning how to make social relationship, how to value and respect others, how to cope with different ideas and how to tolerate conflicts are important factors which should be taken into account by any kind of educational program if it aims to make the learners ready for a prosperous future life.

Consequently, the results of this study confirm the results of the study done by Ghorbani[6], who has tried to determine the impact of cooperative instruction on the writing skill of Iranian EFL learners. He concluded that cooperative instruction compared to traditional method is more effective as a technique for language teaching and leads to better learning.

Similarly the results of this study proved the findings by Razavi[20]. She found out cooperative learning improved reading performance of Iranian University ESP students. She has shown that students who have learned in more student-centered classes had better understanding than those in teacher-dominated classes.

The outcomes of this study were also in line with Liang [18]. The study implemented cooperative learning to EFL teaching. He showed that cooperative learning is a feasible and practical teaching method that puts communicative approach into action. Such a student-centered teaching method helps to improve the students' oral communicative competence of the target language.

\section{Conclusions}

Most EFL teachers concerned about the unsatisfactory outcome of English courses in Iran. It is disappointing and discouraging for them to witness incomplete student performance despite their high efforts to increase the input for better student intake. This problem is remarkable in writing classes, too. Students prefer to have a teacher to solve their writing problems through explanation and translation into the target language. They expect to receive a direct and explicit correction from the teacher. The result is a boring and despairing atmosphere.

One of the solutions to motivating these inattentive learners to master the target language is shifting the responsibility of learning from the teacher to the learners. Nowadays that we consider learners as significant information providers with specific background knowledge, and the effect of socio-cultural factors and interactions in the process of learning, the need for collaboration and cooperation in language classes is undeniable.

The impact of more knowledgeable person on one's language mastery should not be ignored in language pedagogy. This is proved by the significant theoretical viewpoints such as Vygotskyan ZPD. In this regard, creation of conditions under which the learners can be exposed to language and take part in real communication is of great importance. On the other hand, writing skills as a complex and self selected activity can be learned and practiced through the student-student interactional process. That is, writing improvement needs more learner-centered courses due to its being a personalized activity. Respectively, putting the learners in collaborative situation to challenge their own learning is a better way to attain desirable outcomes. This thesis is hoped to sharpen the ideas of those concerned in language pedagogy.

Drawing the results obtained from the present study, it might be concluded that:

1) Cooperative Learning activities improve writing skills in EFL classes.

2) All of the components of a piece of writing i.e. content, organization, vocabulary, language use, and mechanics might be improved though cooperative learning activities.

\section{REFERENCES}

[1] A.Mooore-Hart, M., (1995). The effects of multicultural links on reading and writing performance and cultural awareness of fourth and fifth graders. Retrieved February 6, 2010 From 
http://www.sciencedirect.com/.

[2] Bailey, E.P., Powel, P.A., (2006). Oxford: Oxford University Press.

[3] Brown, H.D., (2001). Teaching by principles (2nd ed.), New York: Longman.

[4] Chafe, A., (1998a). Computer technology and CL, Retrieved October 23, 2008, fromhttp://www.cdli.ca/ achafe/maj-inde x.html.

[5] Gabrielatos, C., (2002). EFL writing: product and process, Retrieved September 19, 2010 from http://www.ERIC.com/.

[6] Ghorbani, M., (2008). The impact of collocational instruction on the writing skill of Iranian EFL learners: A case of product and process, Retrieved September 1, 2010 from http://www.amazon.com/.

[7] Henley, J., (2000). Cooperative learning: It's in there! Retrieved October 23, 2008, from http://tiger.coe.missouri.edu/ vlib/Joan's.stuff/Toan's.pages. html.

[8] Hertz-Lazarowitz, R., \& Bar-Natan, I., (2001). Writing development of Arab and Jewish students using coopeative learning (CL) and computer- mediated communication (CMC), Retrieved February 1,2010 From http://www.sciencedirect.com/.

[9] Jacobs, G. \& Hall, S., (2002). Implementing cooperative learning, in J.C. Richards \& W.A. Renandy (Eds.), Methodology in language teaching, PP. 52-58, Cambridge: Cambridge University Press.

[10] Johnson, D.W., \& Johnson, R., (1974). Instructional goal structure: cooperative, competitive, or Iindividualistic, Review of educational research, 44, 213-240. Retrieved November 20, 2009 Fromhttp://www.clcrc.com/pages/overv iewpapers.html.

[11] Johnson, D., R. \& Holubec, E., (1993). Circles of learning (4th ed.), Edina, MN: International Book Company.

[12] Johnson, D., \& Johnson, R., (1994). An overview of cooperative learning, Retrieved October 8, 2008, from http://www.cooperation.org/pages/html.

[13] Johnson, D., \& Johnson, R., (1998a). Cooperative and social interdependence theory, Retrieved October 8, 2008, from
www.co-operation,org/pages/SIT.html.

[14] Johnson, D., \& Johnson, R., (1998c). Promoting safe educational and community environments: The three Cs programs", Retrieved October 8, 2008, from http://www.co-operation.org/pages/promoting.html.

[15] Johnson, D., Johnson, R., \& Holubec, E., (1998). Cooperation in the classroom, Retrieved November 14, 2009 from http://www.AsianEFLJournals.com/.

[16] Johnson, D., Johnson, R., \& stanne, M., (2000). Cooperative learning methods: A meta- analysis", Retrieved October 23, 2008, from http://www.cooperation.org/pages/CL-methods, h tml.

[17] Kagan, S., (1985). Cooperative learning resources for teacher, Riverside, CA: University of California at Riverside.

[18] Liang, T. (2002). Implementing cooperative learning in EFL teaching: Process and effects, Retrieved December 6, 2009 From http://www.AsianEFLJournals.com/.

[19] Pacurari, O., \& Arad, R., (1995). "Who likes change? Understanding teacher's resistance to pair work", Retrieved October 14, 2009, fromhttp://ettc.uwb.edu.pl/strong/ptt/dec9 5/41Pacura.html.

[20] Razavi, R., (2005). A study of impact of cooperative learning on the reading performance of University ESP student, Unpublished M.A. Thesis, Tabriz: Islamic Azad University of Tabriz Branch.

[21] Rivers, W.M., (1984). Interactive teaching, Cambridge: Cambridge University press.

[22] Slavin, R., (1978). Student Teamstand Achievement Divisions, Journal of research and development in education, 12, PP. 39-49.

[23] Swarts, J. (2004). Cooperative writing: Achieving coordination together and apart, Retrieved September 28, 2009. From http://eltjournals.com/.

[24] Weigle, S. C., (2002). Assessing writing, Cambridge. Cambridge University Press.

[25] Zammuner, V, L. (1995). Individual and cooperative computer- writing and revising: Who gets the best result? Retrieved January 29, 2010 from http://www.sciencedirect.com/. 